\title{
On the predictability of decadal changes in the North Pacific
}

Received: 6 July 1998 / Accepted: 16 October 1999

\begin{abstract}
The predictability of decadal changes in the North Pacific is investigated with an ocean general circulation model forced by simplified and realistic atmospheric conditions. First, the model is forced by a spatially fixed wind stress anomaly pattern characteristic for decadal North Pacific climate variations. The time evolution of the wind stress anomaly is chosen to be sinusoidal, with a period of 20 years. In this experiment different physical processes are found to be important for the decadal variations: baroclinic Rossby waves dominate the response. They move westward and lead to an adjustment of the subtropical and subpolar gyre circulations in such a way that anomalous temperatures in the central North Pacific develop as a delayed response to the preceding wind stress anomalies. This delayed response provides not only a negative feedback but also bears the potential for long-term predictions of upper ocean temperature changes in the central North Pacific. It is shown by additional experiments that once these Rossby waves have been excited, decadal changes of the upper ocean temperatures in the central North Pacific evolve without any further anomalous atmospheric forcing. In the second part, the model is forced by surface heat flux and wind stress observations for the period 1949-1993. It is shown that the same physical processes which were found to be important in the simplified experiments also govern the evolution of the upper ocean in this more realistic simulation. The 1976/ 77 cooling can be mainly attributed to anomalously strong horizontal advection due to the delayed response to persistent wind stress curl anomalies in the early 1970 s rather than local anomalous atmospheric forcing. This decadal change could have been predicted some years in advance. The subsequent warming in the late 1980s, however, cannot be mainly explained by advection.
\end{abstract}

S. Venzke $\cdot$ M. Münnich $\cdot$ M. Latif $(\square)$

Max-Planck-Institut für Meteorologie,

Bundesstraße 55, 20146 Hamburg, Germany

E-mail: latif@dkrz.de
In this case, local anomalous atmospheric forcing needs to be considered.

\section{Introduction}

There is a growing interest in exploring the possibility of predicting decadal climate variations in the North Pacific and North American region. The most prominent longterm swing of the atmosphere-ocean climate system over the North Pacific commenced during the 1976-77 winter season. During this period, the sea surface temperature (SST) cooled in the central North Pacific and warmed off the coast of western North America. Downstream, over the continent of North America, warmer temperatures occurred in the northwest. The change that began in the mid-1970s has been extensively described by many authors (e.g. Miller et al. 1994, 1998; Graham 1994; Trenberth and Hurrel 1994). Several suggestions have been made on how this change came about. Some investigators think of it as a "shift" in climate mean state that was caused by remote forcing from the tropical Pacific Ocean, where a contemporaneous warming of the SST occurred (e.g. Graham 1994; Nitta and Yamada 1989). Trenberth and Hurrel (1994) also emphasize the role of the tropics as the major driving force for the decadal variability in the North Pacific but note also the positive feedback mechanisms in the North Pacific ocean-atmosphere system itself. Miller et al. (1994) conclude from the results of an ocean model simulation that the change in the North Pacific was caused by a unique atmospheric state which persisted before the 1976-77 winter. In their explanation large-scale ocean current advection anomalies acting in concert with largescale heat transfer processes play the major roles. Other researchers argue that the cooling of North Pacific SST in the mid-1970s was not a unique shift, but part of an oscillation with a time scale of a few decades. Latif and Barnett $(1994,1996)$ explain this oscillation in terms of a cycle involving unstable ocean-atmosphere interactions between the subtropical ocean gyre circulation and the 
Aleutian low pressure system. They hypothesize that the atmospheric response to an initial positive SST anomaly in the North Pacific involves a weakend Aleutian low and that the associated anomalous heat flux, reduced ocean mixing, and anomalous Ekman heat transport act as positive feedbacks reinforcing the initial SST anomaly. Furthermore, they argue that in addition to these positive feedbacks the atmospheric response consists of a wind stress anomaly which spins down the subtropical ocean gyre, thereby reducing the poleward heat transport and reversing the SST tendency. In their explanation the decadal time scale of the oscillation is determined by the speed of planetary waves associated with the transient ocean response to the change in the wind stress curl. This hypothesis follows the early ideas of Namias $(1959,1969)$ and Bjerknes (1964) and it is supported by results from other modeling studies $(\mathrm{Xu}$ et al. 1998; Münnich et al. 1998) as well as observations (Zhang and Levitus 1997; Tourre et al. 1999). Results from canonical correlation analysis (CCA, Fig. 1) nicely

a wind stress

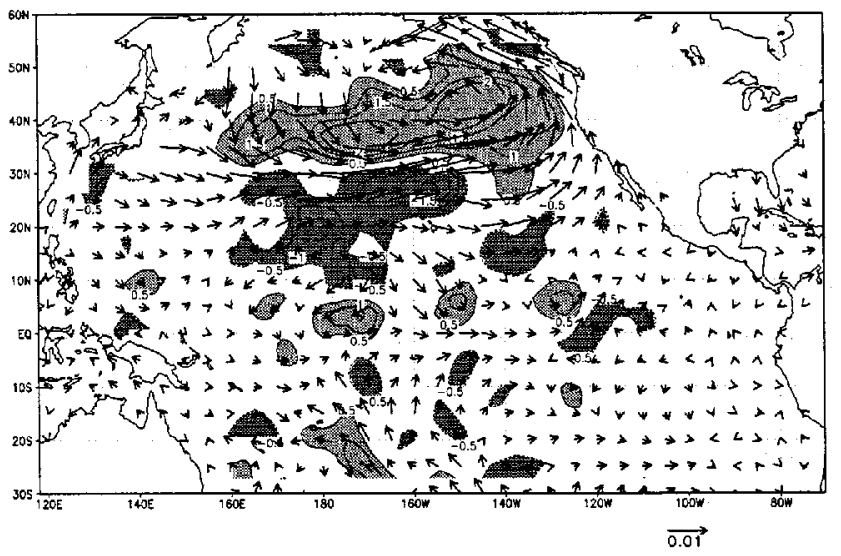

c

SST

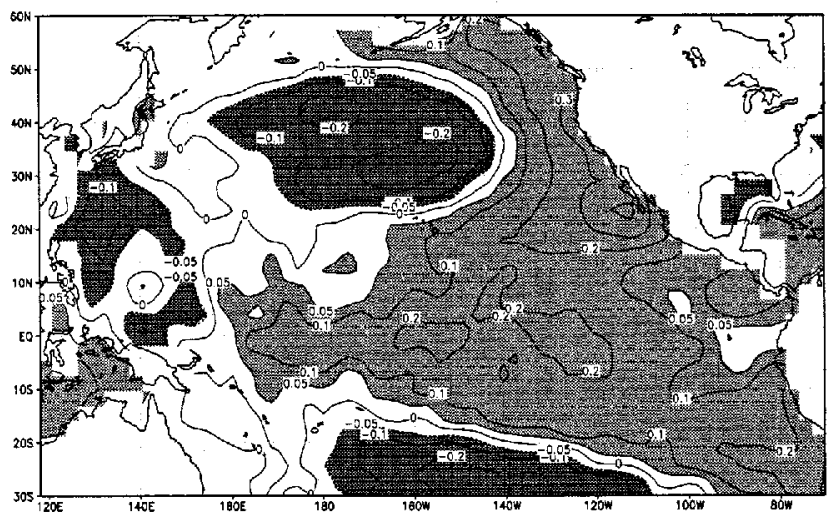

Fig. 1 a-c Patterns and d associated time series of observed decadal wind stress (and wind stress curl, shown as contour lines) and net surface heat flux variability given by the leading mode from canonical correlation analysis (CCA) of anomalous SST (GISST, show the patterns that are associated with observed decadal North Pacific climate fluctuations. They closely resemble the patterns simulated by the coupled model of Latif and Barnett $(1994,1996)$ and are in line with their "gyre mode"-hypothesis. The associated time series reveal a decadal time scale and indicate the existence of an oscillation. An estimate of the period of the oscillation can be obtained form Hurrel's sea level pressure index $\left(30-65^{\circ} \mathrm{N} ; 160^{\circ} \mathrm{E}-140^{\circ} \mathrm{W}\right)$ for this century shown in Fig. 2. Singular spectrum analysis (SSA) reveals a pronounced 18 year oscillation as the leading variability mode.

Although there is a growing interest in the dynamics of decadal climate variability, the question of predicting decadal changes in the North Pacific has not been addressed in great detail so far. We address this question by means of ocean model experiments with idealized and realistic forcing. In particular, we show that the "1976/77 cold shift" was predictable a few years ahead. The work is organized as follows: descriptions

b net surface heat flux

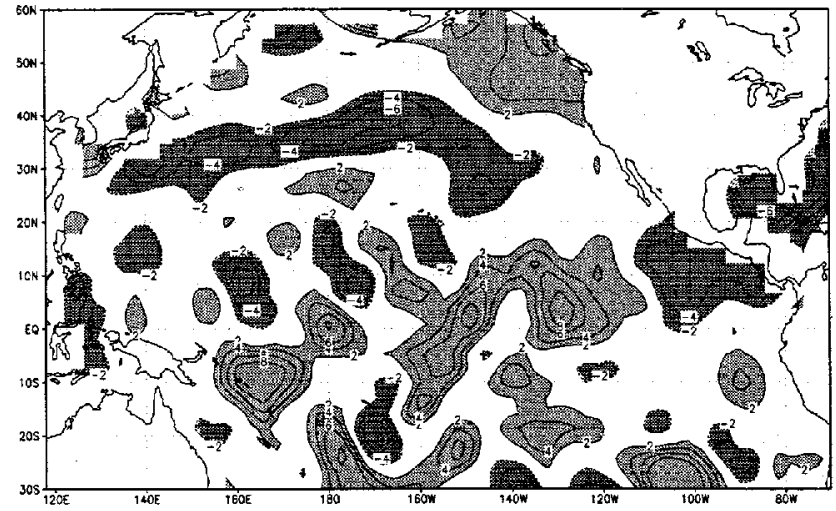

d

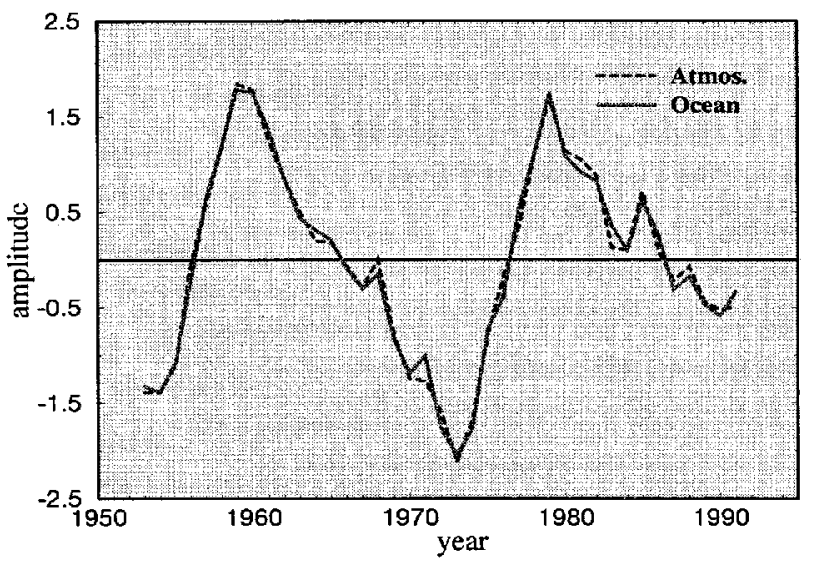

Parker et al. 1995) and the combination of the anomalous atmospheric variables (COADS, da Silva et al. 1994) in winter (DJF). The data was smoothed with a 5 year running mean filter 


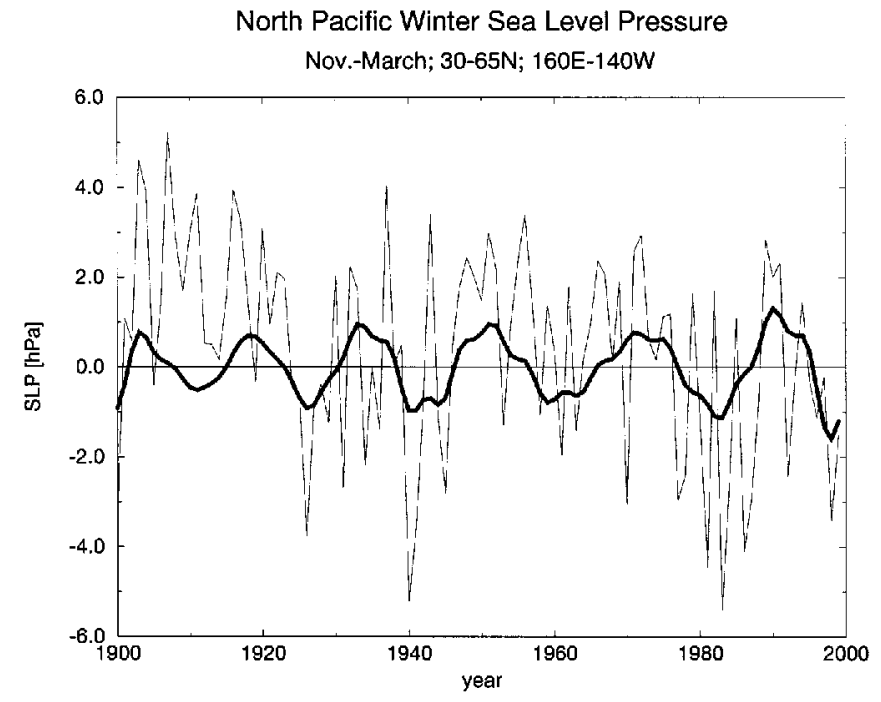

Fig. 2 Time series of observed North Pacific winter sea level pressure (averaged over November-March, $30^{\circ} \mathrm{N}-65^{\circ} \mathrm{N}, 160^{\circ} \mathrm{E}-140^{\circ} \mathrm{W}$ ) after Trenberth and Hurrel (http://www.cgd.ucar.edu/cas/climind/np.html). The thin curve shows the raw data and the thick curve shows the leading mode of variability as derived from SSA, explaining $15 \%$ of the variance

of the ocean model and the atmospheric forcing used are given in Sect. 2. Section 3 deals with the North Pacific response to idealized decadal wind stress variations. In Sect. 4 we show that the main characteristics of this response can also be found when the ocean model is forced by atmospheric observations and we demonstrate how this response can be used to predict decadal North Pacific temperature changes. We conclude the paper with a brief summary and discussion of our major findings in Sect. 5.

\section{Ocean model and experimental design}

To investigate the predictability of decadal changes in the North Pacific we studied the response of a general ocean circulation model to various atmospheric forcing conditions.

\subsection{The ocean model}

The ocean model used is "HOPE" (Hamburg Ocean Model in Primitive Equations) which is based on primitive equations simplified by making use of the hydrostatic and Boussinesq approximations (Wolff et al. 1997). The HOPE model has also been used in coupled mode as described by Frey et al. (1997). In this work we use a domain that is limited to the Pacific Ocean and a realistic bottom topography. The model has a $2.8^{\circ}$ resolution, with the meridional resolution increased to $0.5^{\circ}$ within the region $10^{\circ} \mathrm{N}$ to $10^{\circ} \mathrm{S}$. There are 20 vertical levels which are irregularly spaced with 10 levels in the upper $300 \mathrm{~m}$. The physical parametrization package of the HOPE model includes solar penetration below the surface. About $14 \%$ of the solar radiation incident at the ocean surface is allowed to penetrate beneath the $20 \mathrm{~m}$ surface layer of the model (Paulson and Simpson 1977; Schneider et al. 1997). The vertical mixing is based on a Richardson-number dependent formulation, and a simple mixed layer scheme to represent the effects of wind stirring (see Latif et al. 1994 for details). A Newtonian formulation is employed to restore the surface salinities to the climatology of Levitus (1982) within the whole domain using a time constant of 40 days. No explicit fresh water flux forcing is provided as previous studies (Xu et al. 1998) showed that the fresh water flux only plays a minor role for decadal North Pacific climate variations. The model uses a two hour time step.

\subsection{Atmospheric forcing}

\section{Climatological forcing}

Monthly climatologies of surface heat flux and wind stress data were generated from an AMIP-type integration of the atmospheric GCM ECHAM-3 (Roeckner et al. 1992) forced by observed global sea-ice coverage and sea surface temperatures from the GISST data set (Parker et al. 1995) for the period 1949-93. Daily values, obtained by linear interpolation, are supplied to the ocean model. After initializing the ocean model with three dimensional temperature and salinity fields derived from the climatology of Levitus (1982), it was spun up for 30 years with this climatological forcing, at which point a realistic climatological ocean state was reached for the wind-driven upper Pacific Ocean.

\section{Idealized decadal wind stress changes}

As shown in Fig. 1, large-scale North Pacific SST anomalies are associated with large-scale anomalous atmospheric conditions. A consensus has not yet been reached as to whether these atmospheric anomalies can be mainly attributed to the underlying SST anomalies or are remotely forced by tropical SST anomalies (e.g. Graham et al. 1994; Peng et al. 1997). Latif and Barnett (1994, 1996) used the ECHAM-3 model to study the atmospheric response to a North Pacific SST anomaly, like the one shown in Fig. 1. The resulting wind stress anomaly pattern over the North Pacific and its curl (Fig. 3) resemble quite closely the observed wind stress curl pattern obtained from CCA (Fig. 1). In the experiment discussed in Sect. 3 we superimposed the wind stress pattern shown in Fig. 3 onto the climatogical forcing and varied its amplitude sinusoidally with a period of 20 years.

\section{Observed anomalous atmospheric forcing}

Observed surface heat flux and wind stress anomalies have been derived from the COADS data set for the years 1949 to 1994 (da Silva et al. 1994). We superimposed these onto our climatological forcing of the ocean model in the experiment discussed in Sect. 4. Furthermore, we relaxed the model SSTs to the observations using a time constant of 23 days.

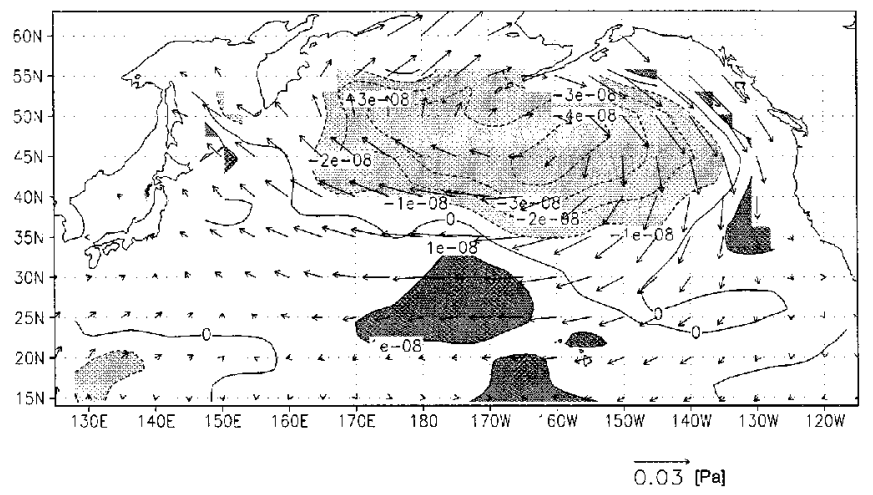

Fig. 3 Response wind stress anomaly $[\mathrm{Pa}]$ and its curl $[\mathrm{Pa} / \mathrm{m}]$ of the atmospheric GCM ECHAM-3 to a large-scale positive SST anomaly in the central North Pacific (see Latif and Barnett 1994 for details) 


\section{North Pacific response to decadal wind stress changes}

The circulation of the North Pacific Ocean is subject to fluctuations on various time scales. In the subtropical gyre, for example, the adjustment time to changes in the wind stress forcing is of the order of weeks for the barotropic mode, while the baroclinic adjustment time scale is several years. As our interest is focused on decadal time scales, only the baroclinic response will be dynamically important. Its transient behaviour is expected to be of relevance for the decadal memory of the climate system. As derived by Gill (1982), the governing equation of the response is the linear potential vorticity equation including a forcing term $F$ equal to the Ekman divergence. It reads on the beta plane at latitude $\theta_{0}$ :

$\frac{\partial}{\partial t}\left(\frac{\partial^{2} \eta}{\partial x^{2}}+\frac{\partial^{2} \eta}{\partial y^{2}}-\frac{f_{0}^{2}}{c^{2}} \eta\right)+\beta \frac{\partial \eta}{\partial x}=F$,

$F=\frac{f}{H}\left(\frac{\partial \tau_{y}}{\partial x}-\frac{\partial \tau_{x}}{\partial y}\right)$.

Here $\eta$ is the sea surface elevation, $c$ is the gravity wave speed of the baroclinic mode considered, $f$ denotes the Coriolis parameter and $\beta=\frac{\partial f}{\partial y}$ its meridional derivative. $H$ is a measure of how well the wind stress projects onto the mode, known as the forcing depth. The zonal and meridional wind stress components are denoted by $\tau_{x}$ and $\tau_{y}$. The free wave solutions of this equation $(F \equiv 0)$ are the planetary Rossby waves. For a plane wave $\eta=\eta_{0} \exp [i(k x+l y-\omega t)]$ the dispersion relation and group velocity $c_{g}$ can be derived from Eq. (1). For the latter one obtains

$c_{g}=\beta \frac{k^{2}-l^{2}-R^{-2}}{\left(k^{2}+l^{2}+R^{-2}\right)^{2}}$

with $R=c / f$ being the Rossby radius. The group velocity reaches its maximum speed $\beta R^{2}$ for the largest scale modes, i.e. if both $k$ and $l$ vanish. For these basinsize waves the group velocities are negative, and the waves are moving to the west. Equation (1) allows eastward travelling waves as well. Their group velocity is about an order of magnitude slower and their wavelengths are too short to be relevant to the large-scale decadal variations considered here. For constant forcing $F$ Anderson and Gill (1975) note two solutions of the forced problem (1). The space independent solution

$\eta(t)=-R^{2} F t$

and the time independent Sverdrup solution

$\eta(x)=F \beta^{-1} x$.

They show how these solutions transform from Eqs. (3) to (4) in response to a suddenly applied wind stress and illustrate numerically how the thermocline is moving uniformly through Ekman pumping (which is equivalent to sea level changes of opposite sign) until boundary effects are felt (In the course of this study we will use sea level anomalies as a measure for the evolution of the anomalous upper ocean heat content.). For sufficiently long continuing forcing, long planetary waves moving westward from the eastern boundary establish a new Sverdrup balance with a uniformly sloping thermocline. The dependence of the group velocity of the long Rossby waves on $\beta$ makes their velocity strongly dependent on the latitude $\theta_{0}$. Assuming a basin size of $100^{\circ}$ longitude, the basin crossing time quadruples from about 5 years in the subtropics near $20^{\circ} \mathrm{N}$ to about 20 years in midlatitudes near $40^{\circ} \mathrm{N}$. By coupling a non-local wind response to thermocline depth anomalies of a simple ocean model that is based on the linear potential-vorticity equation for baroclinic planetary waves Eq. (1), Münnich et al. (1998) produced decadal oscillations. The period of their oscillation amounts to approximately twice the time which the Rossby waves need to travel from the centre of the wind stress curl anomaly to the western boundary. For the wind stress pattern shown in Fig. 3 this would yield a period of roughly 20 years, which is in agreement with the length of the decadal cycle found in observed North Pacific ocean temperature and sea level pressure (Tourre et al. 1999). According to the hypothesis of Latif and Barnett (1994, 1996) the Rossby waves will modify the subtropical gyre circulation in such a way that the heat transport along the Kuroshio and its extension weaken the initial SST anomaly in the central North Pacific leading eventually to the phase reversal. To test this hypothesis we superimposed the characteristic decadal wind stress anomaly pattern shown in Fig. 3 with a sinusoidal period of 20 years onto the climatological forcing of the HOPE model. The resulting sea level anomalies show the same characteristic evolution as revealed by complex empirical orthogonal function (CEOF) analysis of upper ocean heat content observations (Tourre et al. 1999) and coupled ocean-atmosphere models (Latif and Barnett 1994, 1996). While Latif and Barnett $(1994,1996)$ describe a westward propagation in the subtropics and the eastward spreading along the Kuroshio extension, Tourre et al. (1999) focus on the westward propagation in the subtropics and midlatitudes. These three different bands of sea level variability are emphasized in the Hovmöller diagrams of Fig. 4. Westward propagating Rossby waves can be seen in the subtropical North $\mathrm{Pa}$ cific (left panel). Maxima of the sea level anomalies are found slightly to the west of the maxima of the wind stress curl anomaly almost in phase with the amplitude of the forcing. Westward propagating sea level anomalies are also found in midlatitudes (right panel). As the Rossby wave speed is lower at higher latitudes, the sea level anomalies, west of the region of strong wind stress curl anomalies, are lagging behind the forcing amplitude in this region. As expected from the findings of Anderson and Gill (1975), the lag increases towards the west. Close to the western boundary the sea level anomalies in midlatitudes are at their maximum when the forcing is zero (i.e. $90^{\circ}$ out of phase). Between these two bands of westward propagating sea level anomalies there is a 
Fig. 4a-d Hovmöller diagrams of sea level anomalies as obtained from the HOPE model forced by spatially fixed decadal wind stress anomalies from Fig. 3, a following sinusoidal amplitude variations with a period of 20 years. The data has been averaged over $\mathbf{b}$ the subtropical $\left(18-23^{\circ} \mathrm{N}\right)$ and $\mathbf{d}$ midlatitudinal $\left(40-45^{\circ} \mathrm{N}\right)$ North Pacific as well as $\mathbf{c}$ the Kuroshio extension $\left(33-38^{\circ} \mathrm{N}\right)$
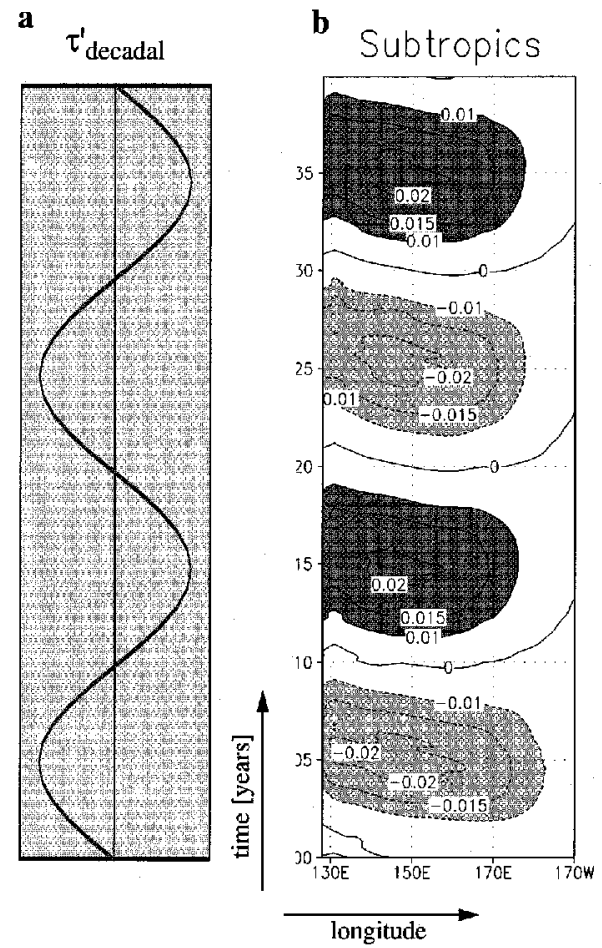

d

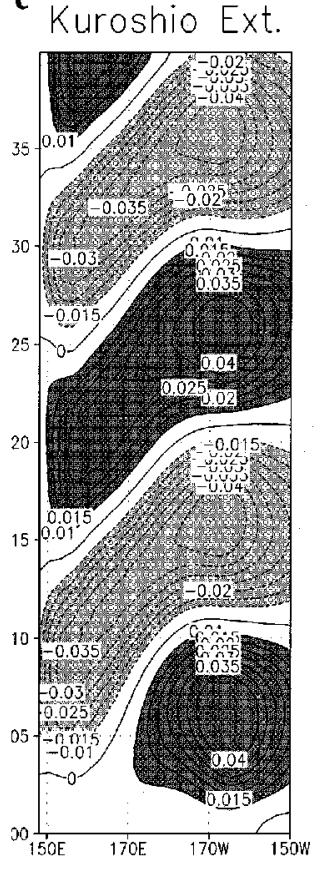

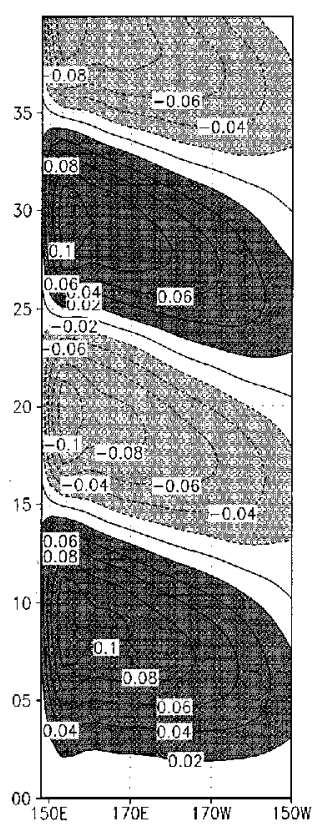

band of almost zero wind stress curl anomalies (Fig. 3) at the latitude of the Kuroshio extension (around $35^{\circ} \mathrm{N}$ ). Here, eastward propagating sea level anomalies are simulated (Fig. 4, middle panel). In the western part of the basin these are not directly forced by local wind stress anomalies but result as a delayed response to the wind stress forcing. It is clear from this figure that the ocean circulation is not in equilibrium with the atmospheric forcing even at decadal time scales.

The delayed response to the anomalous wind stress forcing can be separated from the direct Ekman response by an EOF (empirical orthogonal function) analysis. The first EOF of the anomalous sea level (Fig. 5b) represents the direct response to the wind stress anomalies. It explains $80 \%$ of the total variance and is dominated by large-scale anomalies in the central and northwestern North Pacific which are surrounded by anomalies of opposite sign with highest amplitudes in the subtropics. This situation is described by Tourre et al. (1999) as the end of the "growth phase" of the decadal cycle. The associated principle component (PC) lags behind the forcing by about one year. The second EOF of the anomalous sea level (Fig. 5c) represents the delayed response due to the adjustment of the winddriven ocean circulation. While the sea level anomalies in the northwestern part of the basin have decayed and those in the eastern subtropics moved westward, sea level anomalies of opposite sign have spread from the western subtropical region into the central North $\mathrm{Pa}$ cific. The North Pacific SST anomalies vary in phase with the sea level changes (Fig. 5f). In the Kuroshio extension region, the delayed ocean response associated with EOF-2 involves SST and velocity anomalies shown in Fig. 5d and Fig. 6. From the EOF analyses, as well as from Fig. 6, it becomes evident that even at decadal time scales the North Pacific Ocean circulation and the wind stress curl forcing are not in equilibrium. It is this deviation from the equilibrium, the Sverdrup balance, that provides the delayed negative feedback and hence allows the coupled ocean-atmosphere system to oscillate. An analogous argument proved to be important for the understanding of the ENSO phenomenon, as was shown by Cane and Sarachik (1981) as well as Neelin et al. (1994).

In the "gyre-mode"-hypothesis of Latif and Barnett $(1994,1996)$ the anomalous sea level evolves from the phase described by EOF-1 to that described by EOF-2 through oceanic circulation changes which lead to a reversal of the sign of the SST anomalies along the Kuroshio extension (Fig. 5d). These SST anomalies are presumably amplified by changes of the atmospheric circulation generating sea level and SST anomalies that can be characterized by the patterns of EOF-1 with opposite polarity. As mentioned, the extent to which extra-tropical SST anomalies like those associated with EOF-2 may cause changes of the atmospheric circulation and hence act as a positive feedback, is the subject of ongoing research (e.g. Peng et al. 1997; Venzke et al. 1999) and is beyond our scope here. We shall concentrate on the oceanic circulation changes which provide the negative feedback in the coupled ocean-atmosphere mode of Latif and Barnett (1994, 1996).

Most long-term climate predictions (like El Niño forecasts) rely on the fact that the oceanic initial conditions determine the future evolution of the climate system. The concept of the "delayed-action oscillator" 
a

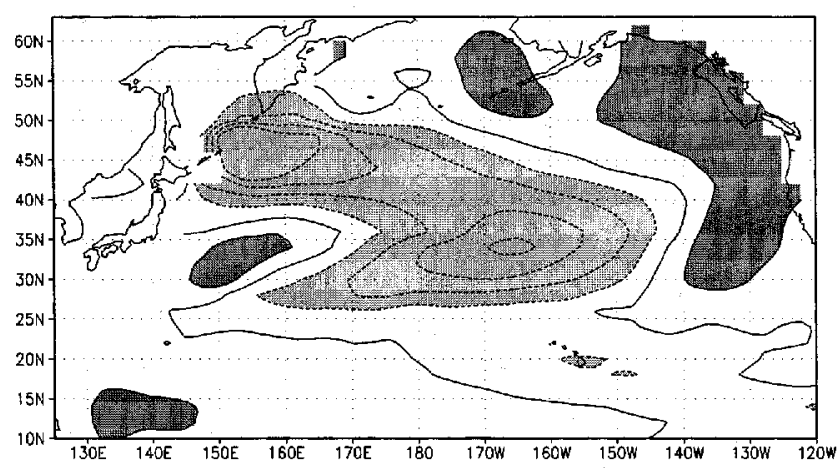

c

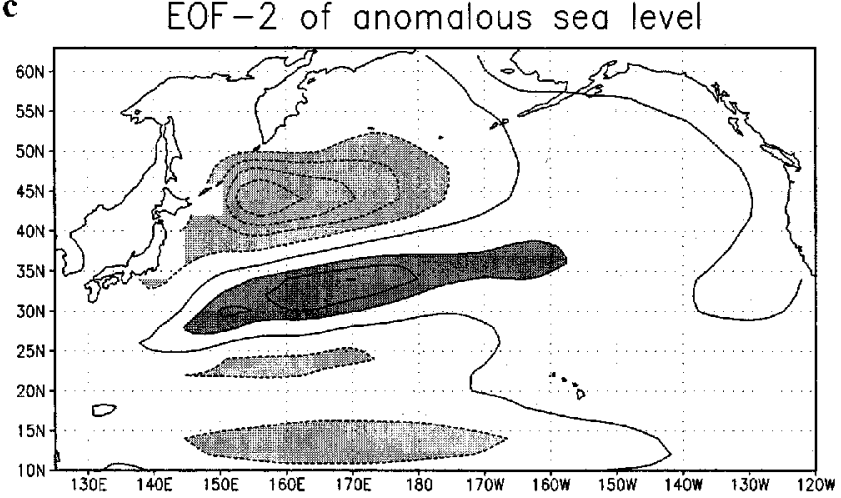

e

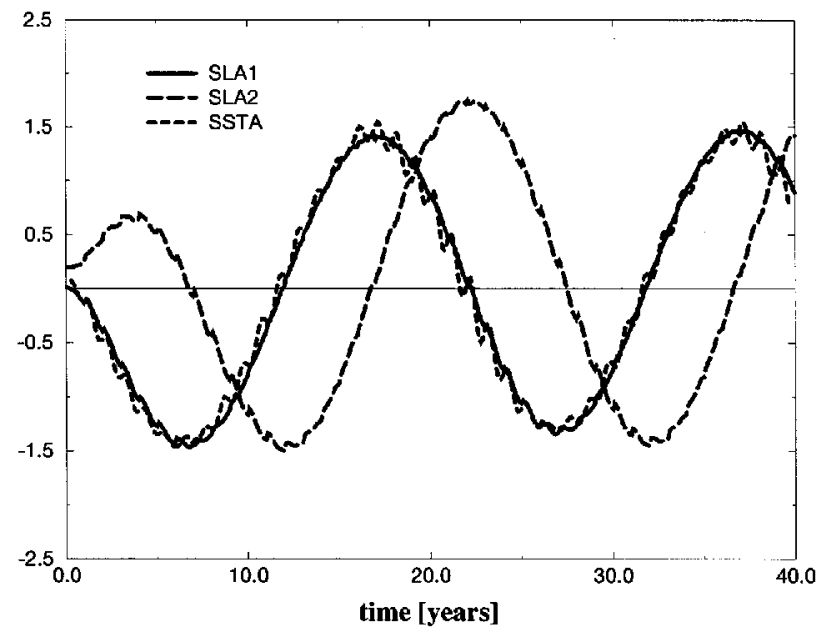

Fig. 5 a First EOF of anomalous SST (explaining $61 \%$ of the total variance), b first EOF of anomalous sea level (80\%), c second EOF of anomalous sea level (17\%) and $\mathbf{d}$ second EOF of anomalous SST

(e.g. Suarez and Schopf 1988) describes the basic dynamics of the ENSO (El Niño/Southern Oscillation) phenomenon. Similarly, the results mentioned suggest that the North Pacific Ocean circulation is not in equilibrium with the anomalous wind stress forcing even at decadal time scales but exhibits a delayed response to the forcing. This means, for instance, that whenever anomalous wind stress conditions similar to those shown in Fig. 3 are observed over a longer period, heat content anomalies of the structure shown in Fig. $5 b$ will estab- b

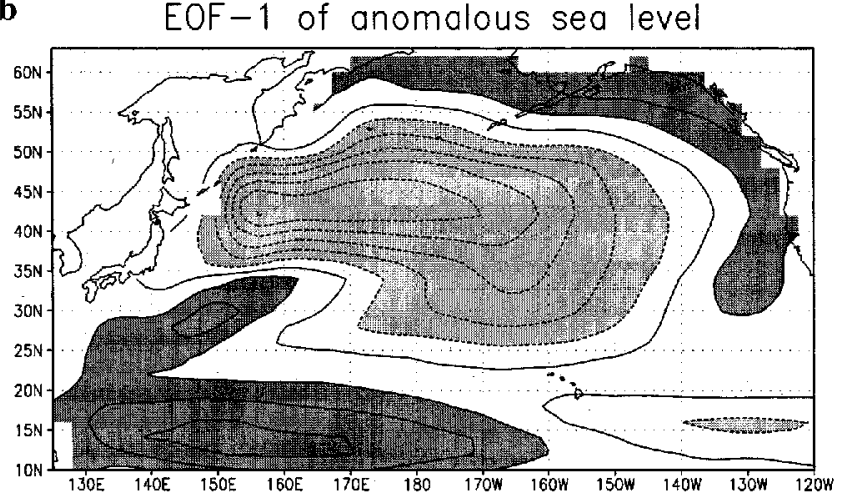

d

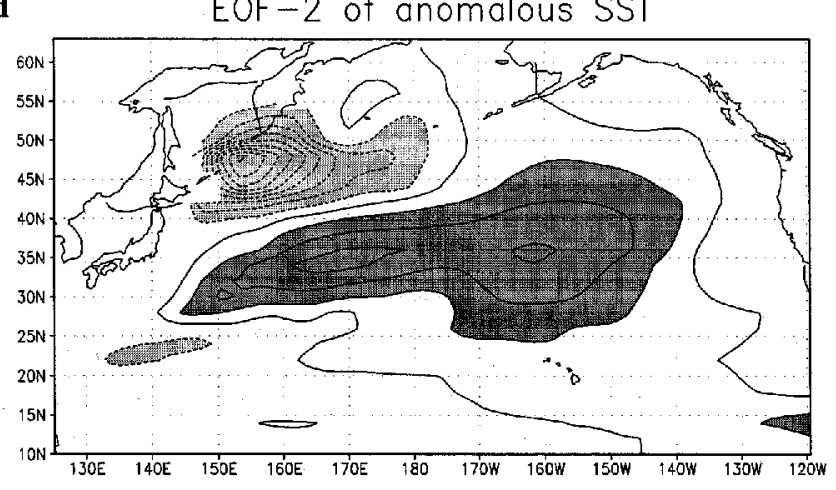

f

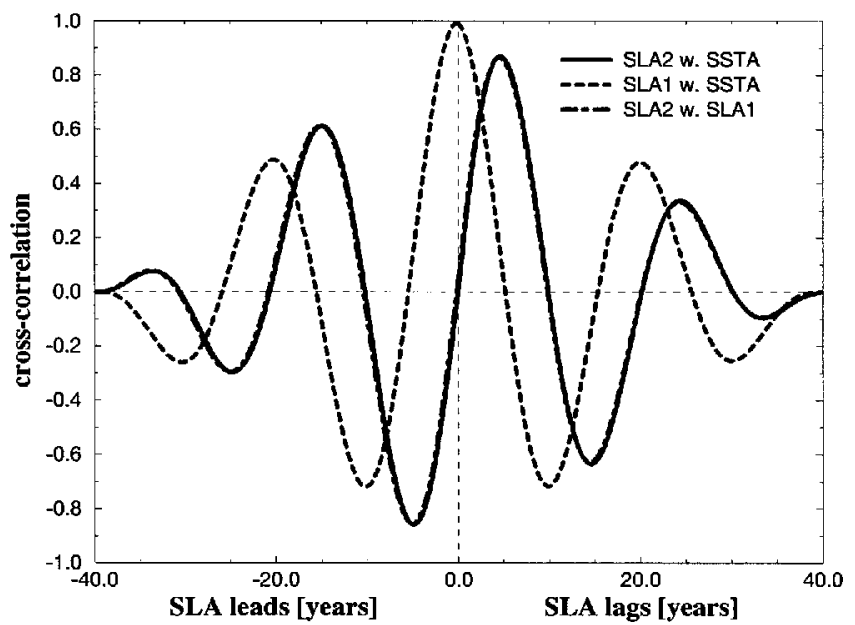

(13\%) together with e the associated principle components and f their lag-correlation functions. The data was obtained from the same experiment as in Fig. 4

lish and evolve into the structure shown in Fig. $5 \mathrm{c}$ in the absence of any further atmospheric forcing. To demonstrate that this evolution is mainly determined by the oceanic initial conditions and does not require any further atmospheric forcing, we performed some additional experiments. In one experiment, the ocean model was initialized after year 28 of the control integration with periodic forcing. At this time EOF-1 had maximum amplitude. Thereafter, the HOPE model was forced by climatological surface heat fluxes and wind stresses only. 
We found that while the subtropical sea level anomalies damp out quite quickly, Rossby wave propagation can be followed for several years in midlatitudes (Fig. 7). In between negative anomalies spread from the western boundary eastward and replace the initial warm conditions in the central North Pacific in a way similar to that in the control integration with periodic forcing. However, due to the lack of atmospheric feedbacks, which in the forced experiment are provided by the prescribed periodicity, they are not amplified and restricted to the western central North Pacific. Projections of sea level anomalies from this ocean-only hindcast onto the EOFs

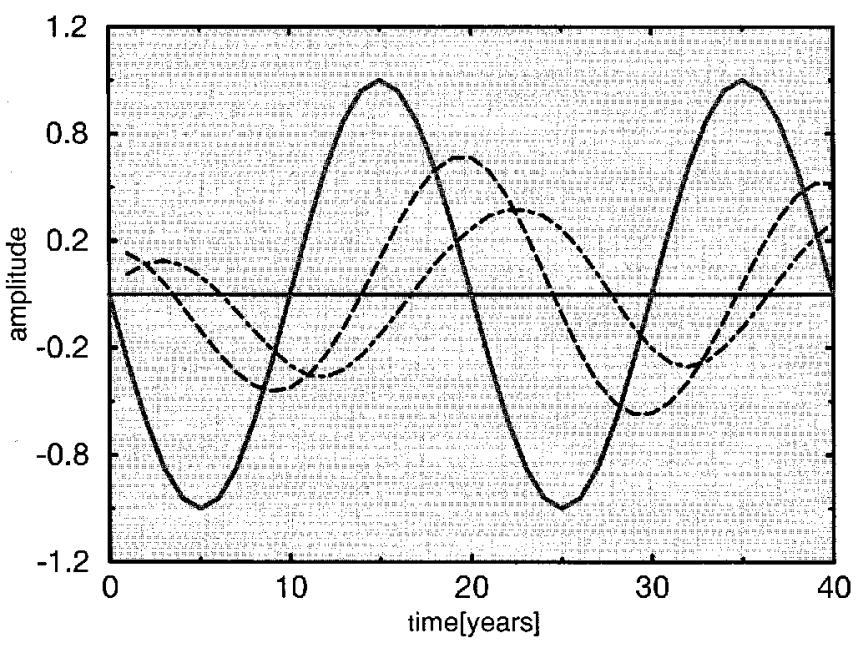

Fig. 6 Solid line, amplitude of the anomalous wind stress pattern shown in Fig. 3; dashed line, amplitude (scaled) of anomalous upper ocean zonal velocity (averaged over $33^{\circ} \mathrm{N}-38^{\circ} \mathrm{N}, 150^{\circ} \mathrm{E}-170^{\circ} \mathrm{E}$, 0-250 m). Dashed-dotted line, anomalous SST averaged over $33^{\circ} \mathrm{N}-$ $38^{\circ} \mathrm{N}, 150^{\circ} \mathrm{E}-170^{\circ} \mathrm{E}$ of Fig. 5 reveal that while the principal component of EOF-1 is monotonically decaying, the principal component of EOF-2 grows (starting from zero) for three years before it starts to decay. This confirms that changes in the oceanic circulation can provide the negative feedback required in a coupled ocean-atmosphere mode like that proposed by Latif and Barnett (1994, 1996). If the model is initialized with opposite polarity (e.g. after year 15) the sea level anomalies evolve in the same way but with opposite sign. This proves that the cooling of the central North Pacific found in the hindcasts that was initialized after year 28 does not simply reflect a general tendency of the model to cool when the anomalous forcing is switched off.

In summary, the results from these idealized experiments indicate that long-term changes of the central North Pacific upper ocean temperature may be predicted from initial oceanic conditions a few years ahead. One should note at this point, however, that such predictability is limited by atmospheric variability on various time scales, generating additional oceanic perturbations. In the next section, we shall show that nevertheless the characteristics of the discussed oceanic variations can also be found in a realistic simulation of the North Pacific upper ocean temperatures, and that hence certain decadal changes could have been predicted.

\section{Predictability of observed decadal North Pacific temperature changes}

While idealized atmospheric forcing was used in the previous section to demonstrate the potential to predict
Fig. 7a-c Hovmöller diagrams of sea level anomalies from ocean-only experiments initialized after year 15 and year 28 of the experiment discussed in Figs. 4-6 averaged over the same regions as in Fig. 4

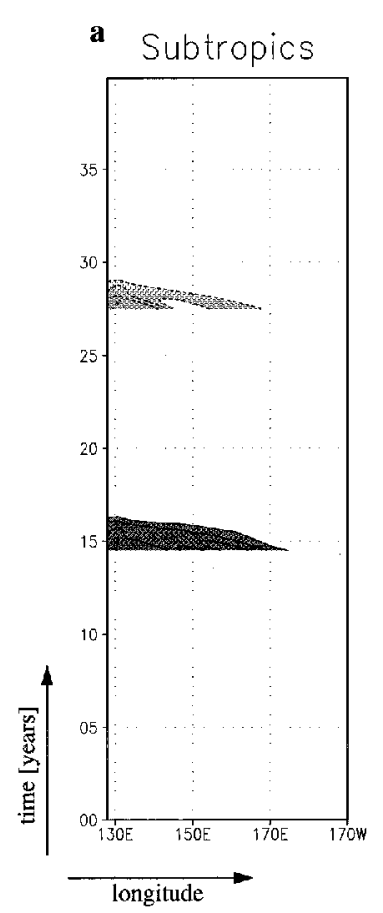

b Kuroshio Ext.

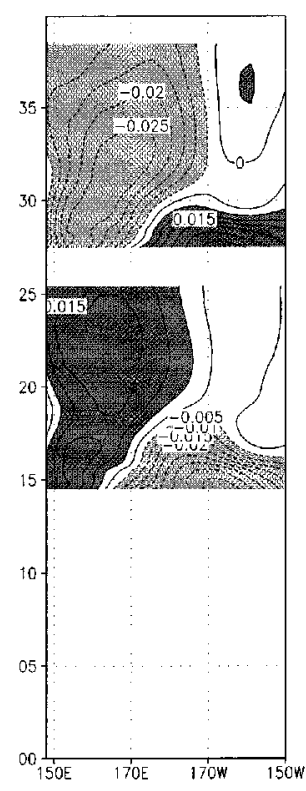

c Midlatitudes

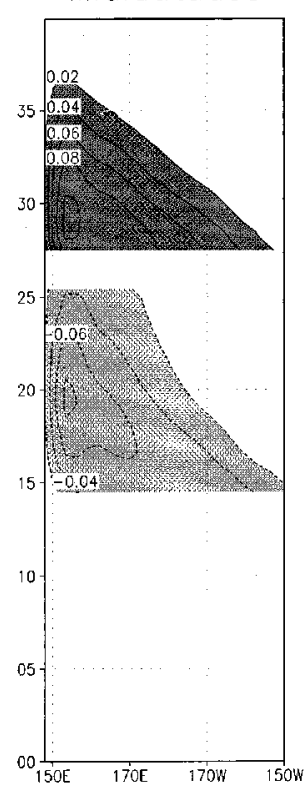


decadal changes in the central North Pacific from oceanic initial conditions only, we shall demonstrate in this section that the same applies when realistic atmospheric forcing is used. In analogy to Fig. 4, Fig. 8 shows Hovmöller diagrams of sea level anomalies, which were obtained from a simulation in which the HOPE model was forced by observed wind stress and heat flux anomalies for the period 1949-1993 (da Silva 1994) superimposed on the climatological forcing described already. This simulation reproduces the observed North Pacific upper ocean temperature evolution remarkably well (see Schneider et al. 1999a). In agreement with the findings of the previous section, westward propagating see level anomalies are found in the subtropics and midlatitudes while, especially during the late 1970s and late 1980 s, sea level anomalies tend to propagate eastward in the region of the Kuroshio extension. An EOFanalysis confirms the findings presented above for the case of idealized forcing. Figure 9 shows in analogy to Fig. 5 that the long-term sea level variability can be separated into a direct and a delayed response which are described by the first two leading EOFs. The first and the second PCs of the anomalous sea level have their maximum correlation (significant at the $95 \%$ confidence level) when PC-1 leads PC-2 by about 8 years and their maximum anti-correlation (significant at the $90 \%$ confidence level) when PC-1 lags PC-2 by about 8 years. Consistent with the results from the idealized forcing experiment, EOF-1 represents the direct response and sets the conditions for the delayed response (EOF-2), which in turn is a precursor of EOF-1 with the opposite sign. The lag is slightly longer than that in the simplified experiment (which by design was 5 years) but is consis- tent with findings from Zhang and Levitus (1997) who investigated observed upper ocean temperature measurements. Further deviations from the idealized experiment, like the unsymmetric cross-correlation between the dominant modes of SST and sea level variability, reveal that the real ocean-atmosphere system exhibits only quasi-periodic decadal changes which can only be characterized by an idealized periodic simulation to a first approximation. However, we next investigate the predictability of the decadal upper ocean temperature changes that occurred during the late 1970s and 1980s in the central North Pacific.

The most prominent long-term temperature change occurred in the North Pacific in the late 1970s (Fig. 8, middle panel) which is often referred to as the "1976/77 cold shift". Subsurface cooling in the Kuroshio extension area during that time was identified in various studies (e.g. Deser et al. 1996; Miller et al. 1998; Zhang and Levitus 1997) and is simulated well by our model (Figs. 8, 9 and Schneider et al. 1999a). Negative sea level anomalies develop around 1965 in the eastern subtropical North Pacific and spread westward (Fig. 8). At the same time, anomalies of opposite sign develop in midlatitudes which also propagate westward (at lower speed as explained already). Both anomalies can be clearly attributed to large-scale wind stress curl anomalies similar to those used in the previous section (Fig. 3) which persisted for about a decade (Fig. 10a). We hypothesize that they led to an adjustment of the subtropical gyre circulation (Fig. 10c) which caused the cooling in the Kuroshio extension region during the late 1970s. This conclusion is also supported by a recent study a Deser et al. (1999). From the observed upper
Fig. 8a-d Same as Fig. 4 but for the simulation in which the HOPE model was forced by observed atmospheric wind stress and surface heat flux anomalies. The sea level data has been smoothed with a 5 year running mean filter
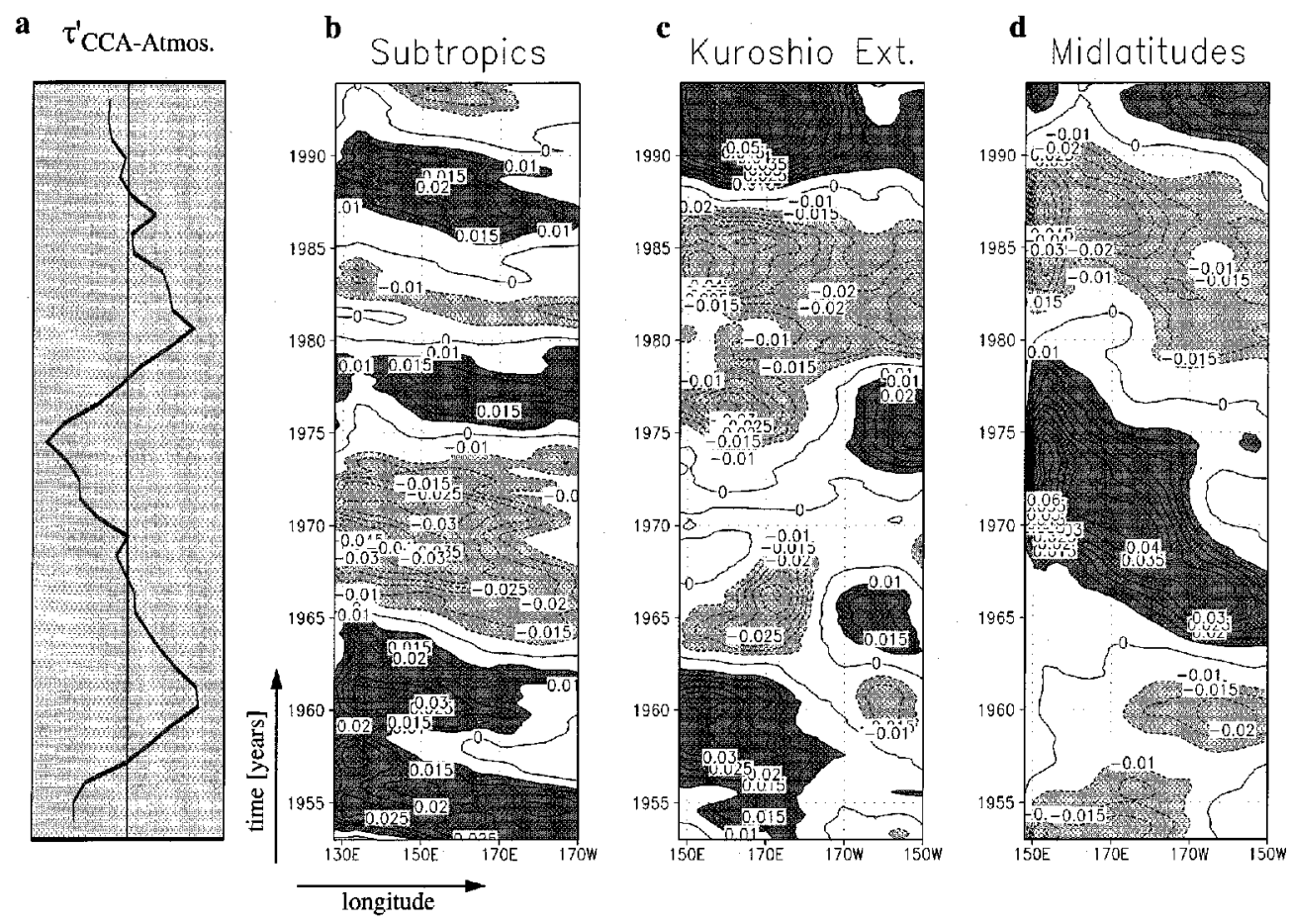
a

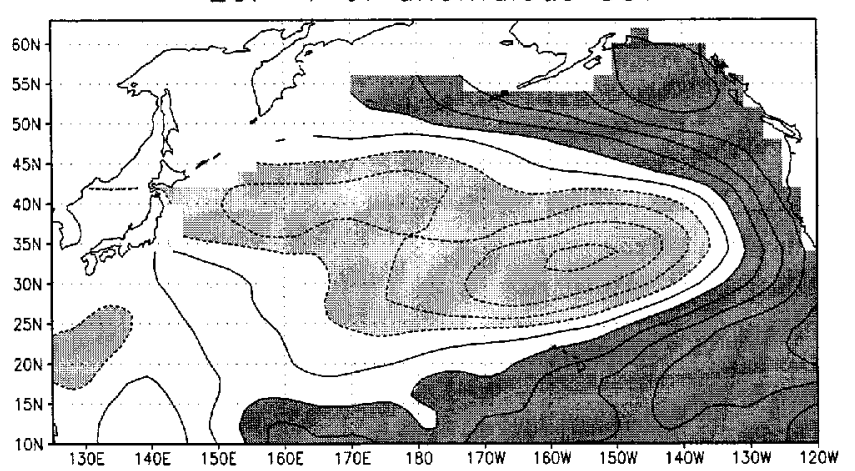

c

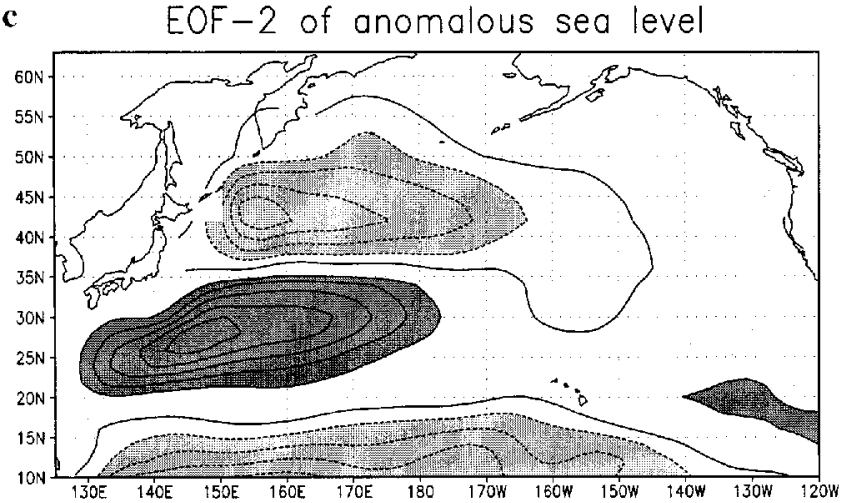

e

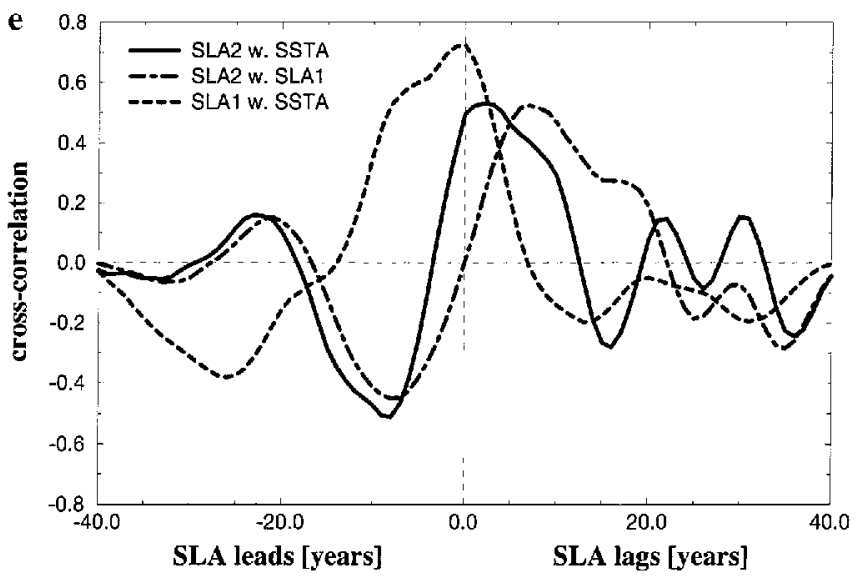

ocean thermal field they nicely document an enhanced eastward geostrophic flow along the southern flank of the Kuroshio Current extension during the 1980s relative to the 1970s as a result of the dynamical adjustment of the midlatitude oceanic gyre circulation to a decadalscale change in wind stress curl. Consistently, they find a 4-5 year delay between the ocean response and the basin-wide wind stress curl changes. Although our model generally underestimates the strength of the Kuroshio and its extension due to the relatively coarse model resolution, the relative strength of the circulation change compares well with that inferred by Deser et al. (1999).
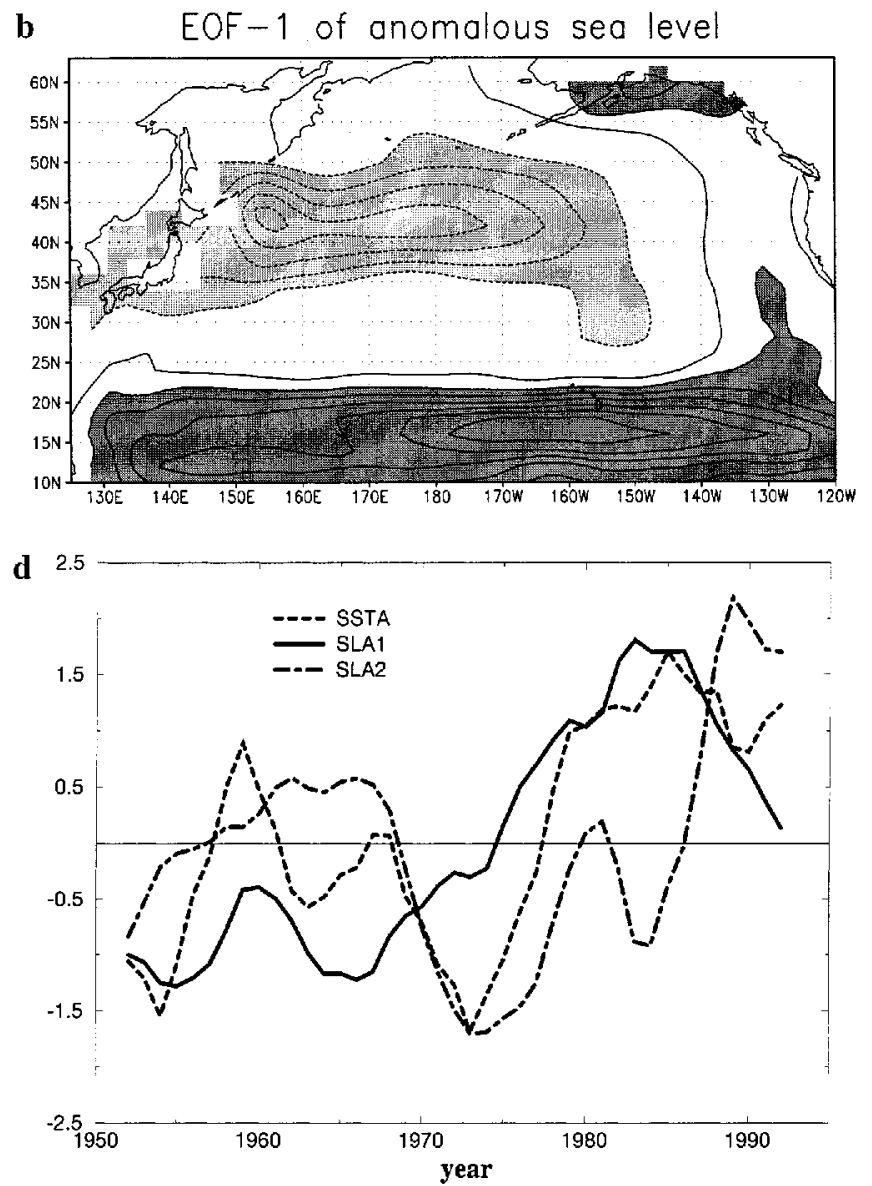

Fig. 9 a First EOF of anomalous SST (explaining $45 \%$ of the total variance), b first EOF of anomalous sea level (43\%) and $\mathbf{c}$ second EOF of anomalous sea level (19\%) together with $\mathbf{d}$ the associated principle components and $\mathbf{e}$ their lag-correlation functions. The data was obtained from the same experiment as in Fig. 8 and has been smoothed with a 5 year running mean filter

If our findings from the previous section are applicable to the realistic simulation, then we should be able to hindcast the observed cooling. We initialized the ocean model with the three dimensional temperature, salinity and current structure simulated in December 1975 and integrated the model forward using the climatological surface heat fluxes and wind stresses only. Consistent with the results from the simplified experiment described in the previous section, negative sea level anomalies spread eastward along the area of the Kuroshio extension into the central North Pacific (Fig. 11b). Note that the subtropical and midlatitudinal anomalies 
a

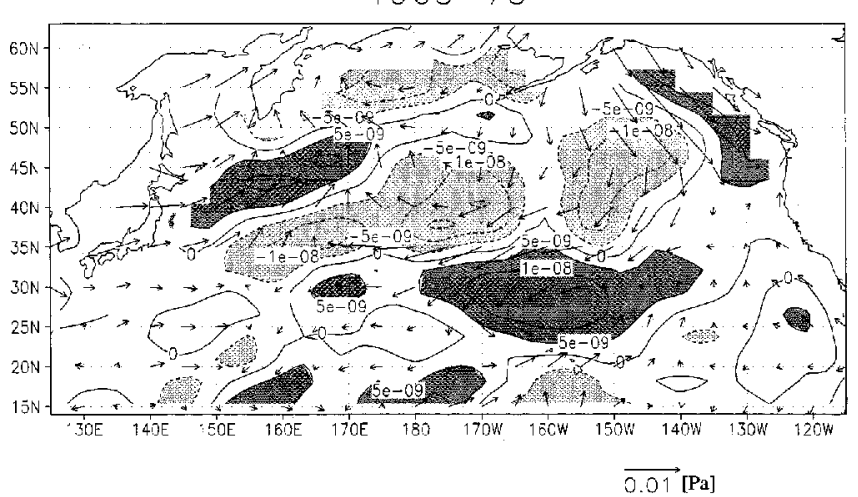

c

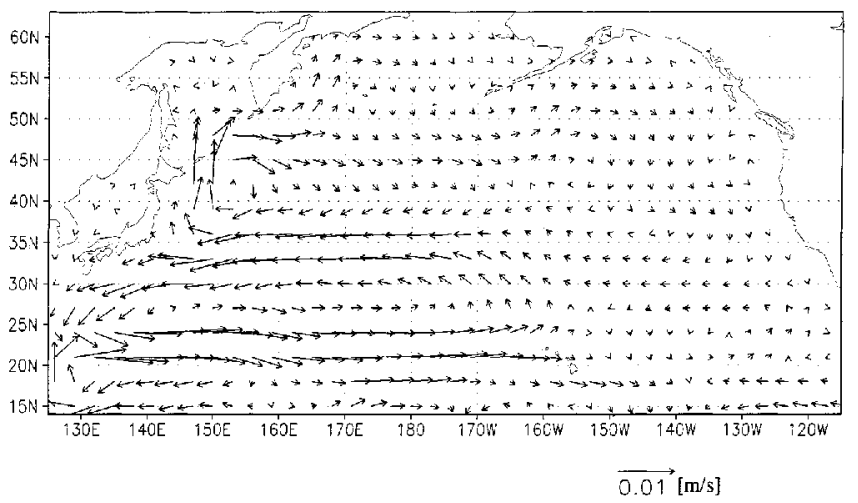

Fig. 10a-d Observed wind stress $[\mathrm{Pa}]$ and wind stress curl $[\mathrm{Pa} / \mathrm{m}]$ anomalies (deduced from the COADS data set) averaged over the periods a 1965-1975 and b 1977-1987 as well as anomalous upper

(Fig. 11a, c) do not resemble those of the control experiment quite so well as these regions are mainly governed by the direct response to the anomalous wind stress forcing. The predicted sea level changes in the central North Pacific, however, follow those simulated in the integration with observed forcing quite closely (Fig. 12). These results confirm that the observed "1976/ 77 cold shift" in the central North Pacific can indeed largely be explained by the adjustment of the North Pacific Ocean circulation to decadal wind stress curl changes and to a lesser extent by local forcing which is also supported by the findings of Miller et al. (1994). Furthermore, they demonstrate that the "1976/77 cold shift" was indeed predictable a few years ahead.

In the late 1980s the cold conditions in the central North Pacific terminated. Again, the conditions for the temperature change appeared to be set by wind stress anomalies occurring during and after the "1976/77 cold shift" (Fig. 10b). The resulting Rossby waves contributed in midlatitudes to the mature North Pacific cold phase during the 1980s and in the subtropics to the surrounding anomalously warm conditions (Fig. 8). The overall effect of the Rossby wave propagation is again an adjustment of the gyre circulation (Fig. 10d). In order to investigate whether this allows us to hindcast the b

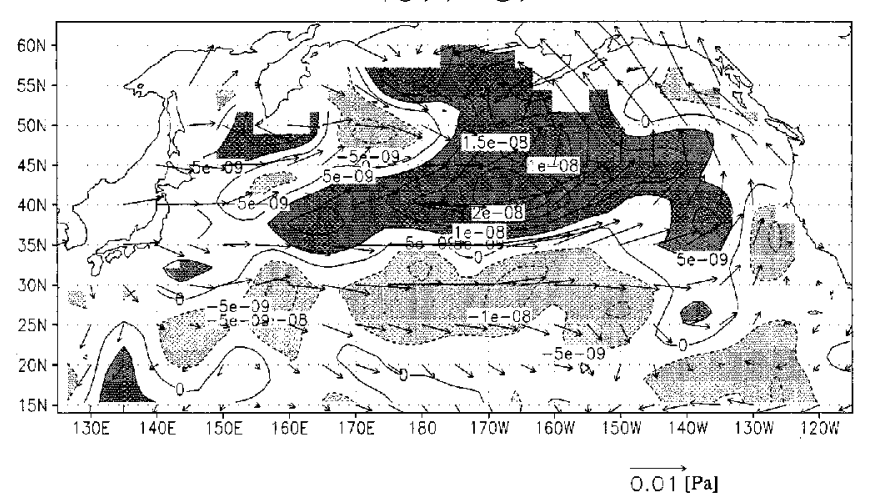

d

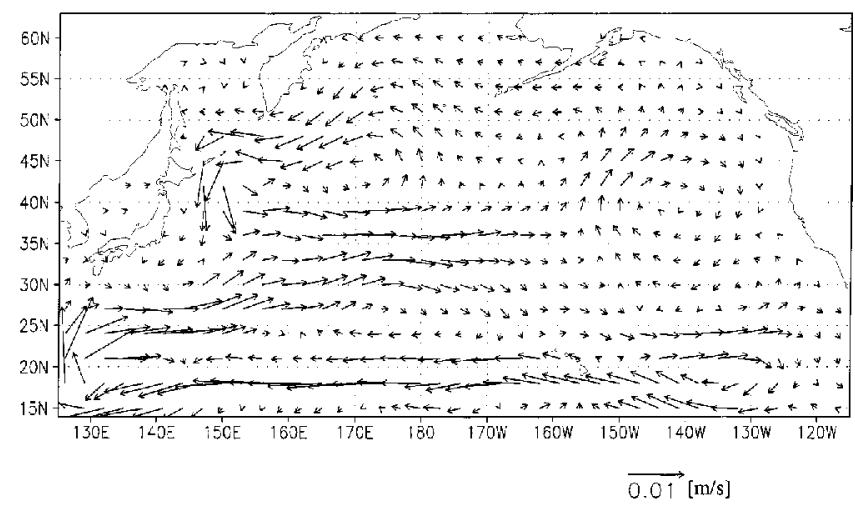

ocean $(0-300 \mathrm{~m})$ velocities $[\mathrm{m} / \mathrm{s}$ ] from the HOPE model forced by observed atmospheric conditions averaged over the periods c 1972-1975 and d 1985-1987

observed warming in the central North Pacific, we initialized the HOPE model in December 1987 and integrated it forward with climatological forcing only. The resulting sea level evolution is included in Fig. 11. The comparison with the integration using observed forcing (Fig. 8) reveals that in this hindcast the positive heat content anomalies in the region of the Kuroshio extension in the late 1980s are too confined to the western part of the basin. There is, however, some indication of eastward propagation. Unlike the hindcast of the cooling in the late 1970s the sea level change in the central North Pacific is underestimated (Fig. 12). This suggests that for this case the delayed wind stress response accounts for a smaller fraction of the observed change relative to the 1976/77 cooling. The second driving agent for upper ocean temperature changes are the local anomalous atmospheric variations. Decadal wind stress curl anomalies are generally small at the latitude of the Kuroshio extension (Figs. 3 and 10). They do, however, also effect the upper ocean temperature structure through anomalous Ekman currents. In fact, negative wind stress curl anomalies prevailed from 1987 until the early 1990 s around $35^{\circ} \mathrm{N}$ (not shown). They deepened the thermocline and helped to enhance the upper ocean temperatures in the central North Pacific. This contri- 
Fig. 11a-c Hovmöller diagrams of sea level anomalies from ocean-only hindcasts initialized in December 1975 and December 1987 from the control experiment discussed in Figs. 8 and 9 averaged over the same regions as in Fig. 8. The sea level data has been smoothed with a 13 month running mean filter

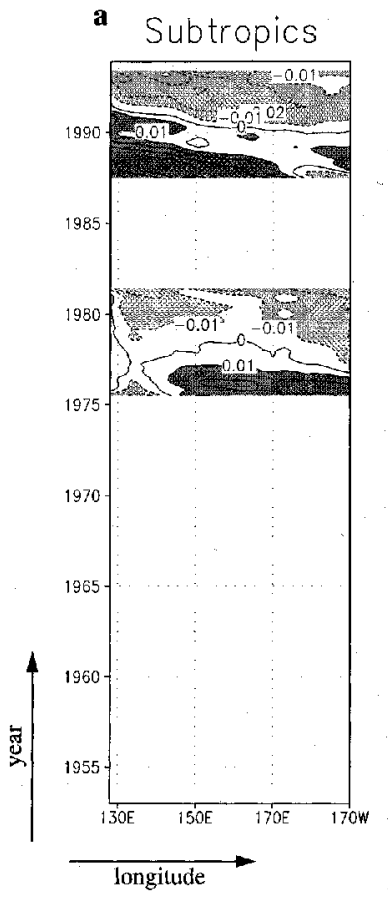

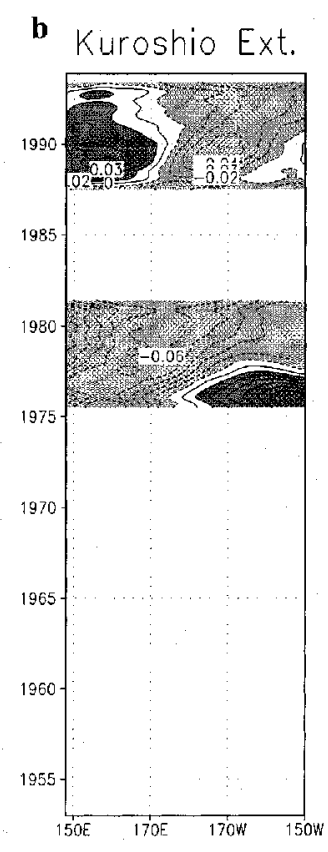

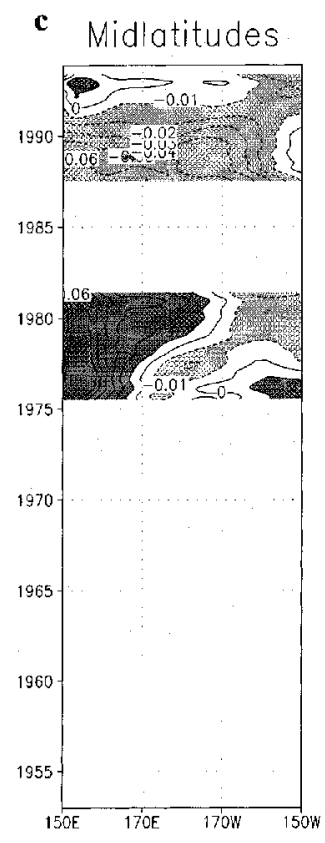

\section{Central North Pacific anoamlous sea level $32-42 \mathrm{~N} ; 180-160 \mathrm{~W}$}

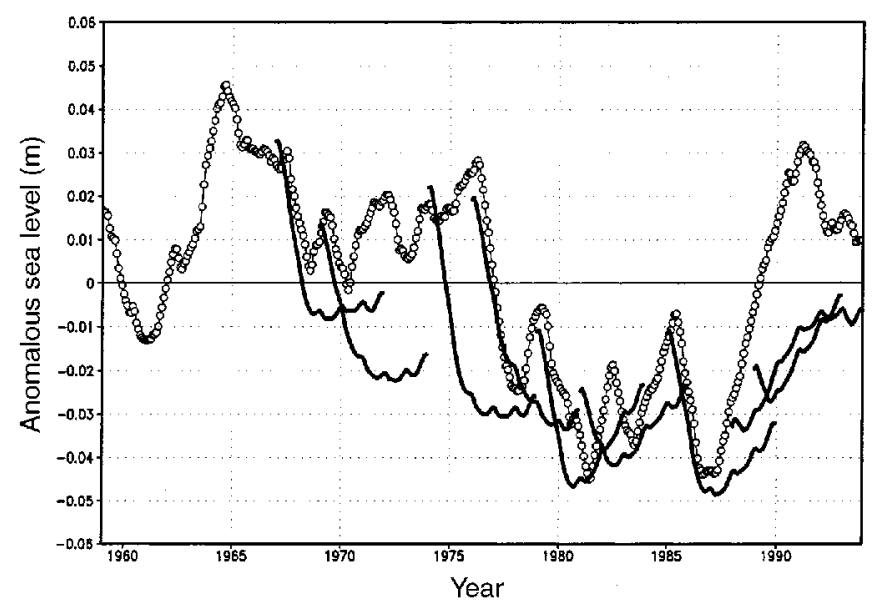

Fig. 12 Central North Pacific $\left(32-42^{\circ} \mathrm{N}, 180-160^{\circ} \mathrm{W}\right)$ sea level anomalies [m] as simulated by the HOPE model in the COADS experiment (open circles) as well as in ocean-only hindcast experiments (black lines). The data was smoothed with a 13 month running mean filter

bution is, by design, not considered in our hindcast experiments in which changes resulting from preceding wind stress anomalies only contribute to upper ocean temperature changes. This may explain why the full extent of the warming is not captured in our simple hindcast experiment.

In order generalize the findings of these case studies and to quantify the hindcast skill, seven additional hindcasts were initialized in December of the years 1966,
1968, 1973, 1978, 1980, 1984 and 1988. Figure 12 shows central North Pacific index time series from the COADS simulation and all hindcasts. While the hindcasts show some skill in predicting the sea level evolution in this index region during the late 1970s and early 1980s, they largely fail during the late 1960s and early 1970s. To obtain a more complete picture of the hindcast skill, the actual skill score of the hindcast ensemble has been computed at every grid point for different lead-times. As can be seen in Fig. 13, the skill of the hindcasts exceeds that of the persistence forecast over large parts of the North Pacific. In the western region the delayed response of the North Pacific gyre circulation to previous wind stress forcing provides significant skill for predicting the sea level evolution several years ahead. As discussed, local atmospheric forcing plays an important role for sea level changes in the eastern North Pacific. Since no atmospheric feedback is included in the hindcast experiments, this limits the prediction skill of our system. In summary, the 1976/77 cooling can almost entirely be attributed to the delayed response to basinwide wind stress curl anomalies that prevailed over the foregoing decade. It represents a good example of how ocean dynamics enable a successful hindcast of decadal climate changes.

\section{Summary and discussion}

We investigated the oceanic processes that are essential for the existence of a coupled North Pacific air-sea mode of decadal climate variability according to the hypothesis of Latif and Barnett $(1994,1996)$. Using integrations with a complex ocean general circulation model under 

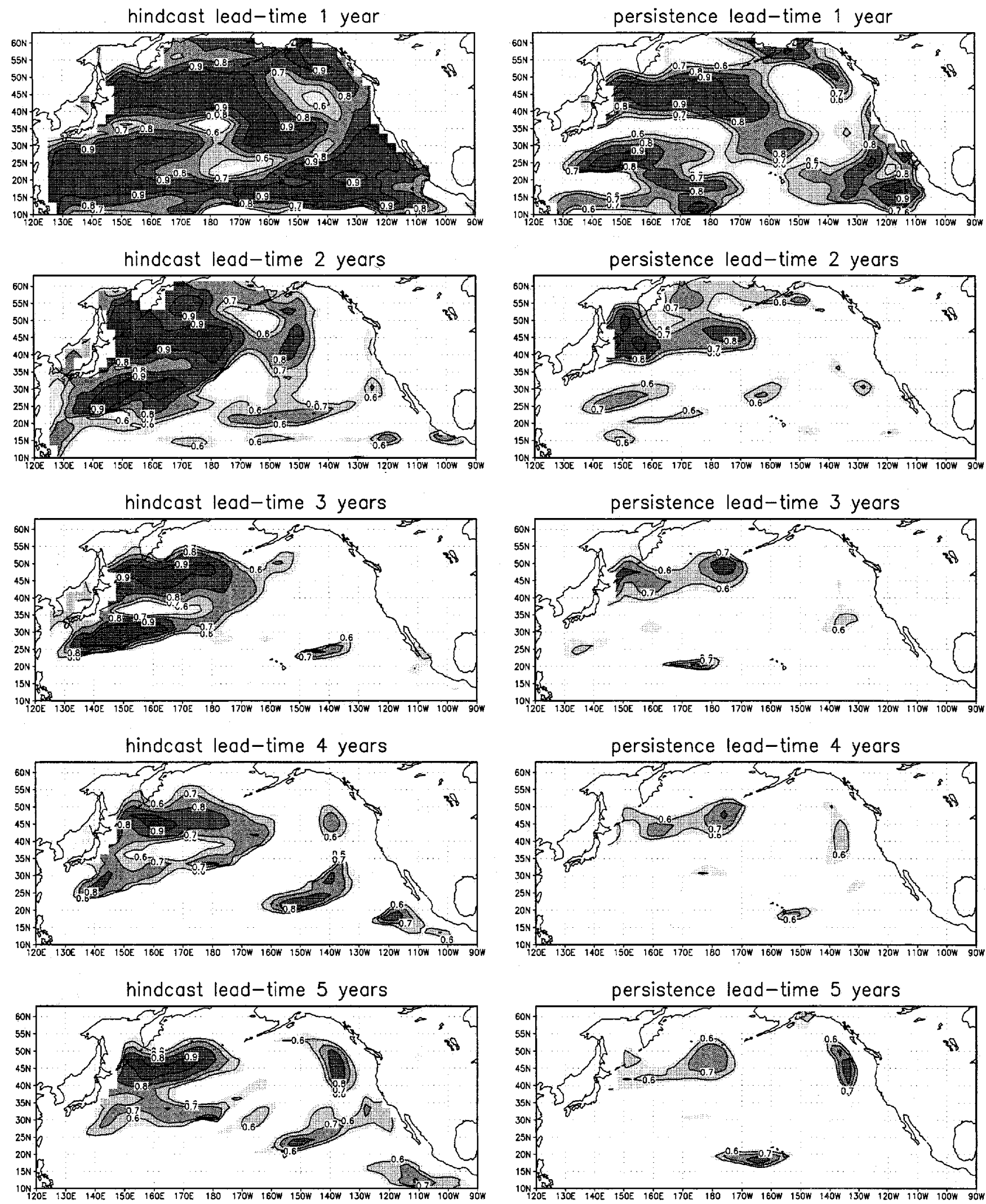

Fig. 13 Left panels: correlation coefficients (skill score) of annual sea level anomalies as simulated in the COADS experiment and as predicted in the hindcast experiments for different lead-times

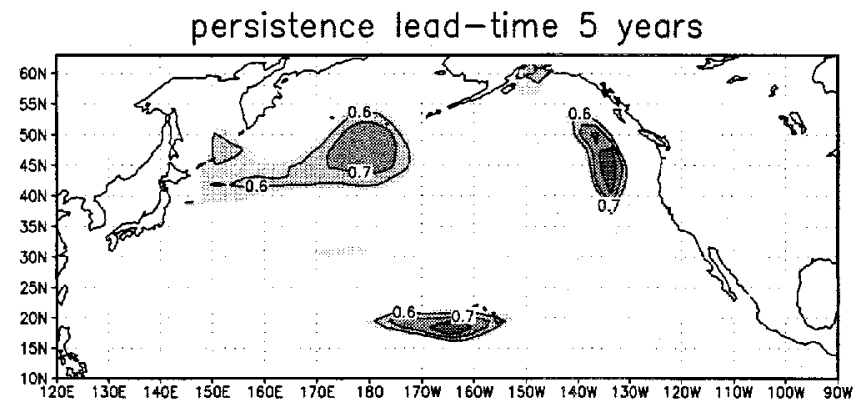

(plotted only, where significant at the $95 \%$ confidence level). Right panels: equivalent correlation coefficients obtained by assuming persistence 
simplified and realistic atmospheric forcing conditions we found that the ocean's response to anomalous decadal wind stress forcing does indeed involve the dynamical processes proposed by Latif and Barnett $(1994,1996)$ and showed that these can be exploited for the prediction of decadal climate changes. Baroclinic Rossby waves dominate the response mainly in the subtropics (around $20^{\circ} \mathrm{N}$ ) and midlatitudes (around $45^{\circ} \mathrm{N}$ ). They propagate westward causing an adjustment of the North Pacific gyre circulation. The latter leads to changes in the heat transport along the Kuroshio and its extension which affects the upper-ocean temperatures of the central North Pacific. The theoretical description of the adjustment of the gyre circulation to basin-scale wind stress changes was originally given by Anderson and Gill (1975), and its relevance for decadal climate variations was stressed by Münnich et al. (1998) and Deser et al. (1999). In the study by Münnich et al. (1998), however, the ocean model dynamics did not include any advective processes. It could therefore simulate only the westward propagation of the Rossby waves, but not the delayed eastward spreading of anomalous heat content along the Kuroshio extension. Tourre et al. (1999) found both in their analysis of observed upper ocean heat content anomalies i.e., the westward propagation in the subtropics and midlatitudes as well as the eastward spreading along the $\mathrm{Ku}$ roshio extension. They note, however, that the westward propagating signal in the subtropics is much stronger than the one spreading eastward along the Kuroshio extension. This is consistent with our results from the simplified forcing experiment and the simulation with the observed atmospheric forcing. The delayed eastward spreading response, however, is important as a negative feedback mechanism in a decadal coupled air-sea mode as proposed by Latif and Barnett (19994, 1996). Furthermore, it provides the possibility to predict decadal changes of upper ocean temperatures in the central North Pacific a few years in advance.

The sea level anomalies simulated in the ocean model run with observed atmospheric wind stress and heat flux anomalies exhibit similar characteristics as found in the idealized run with periodic decadal forcing. These results support again the hypothesis of Latif and Barnett (1994, 1996). It becomes evident from that simulation and the ocean-only hindcast experiments that the cooling which occurred in the central North Pacific in the late 1970s can be attributed largely to the anomalous gyre-circulation and therefore could have been predicted from the state of the western North Pacific a few years before. Since the cooling is reproduced in the ocean-only hindcast although atmospheric feedbacks are neglected, anomalous horizontal advection of heat appears to be the main agent for the central North Pacific cooling. Miller et al. (1994) concluded from an ocean model simulation that the 1976/77 cold shift was caused mainly by anomalously strong horizontal advection and maintained by anomalous vertical mixing and heat flux. Furthermore, Miller et al. (1998) also present evidence that the observed thermocline cooling is part of a basinscale pattern of adjustment to the wind stress curl forcing. From simple gyre-scale circulation theory and the wind stress observations they derive the theoretical streamfunction and obtained the similar gyre-scale circulation change from the early 1970s to the late 1980 s that we found (Fig. 10). Our results support these findings.

Our results also suggest that in the late 1980s anomalous horizontal advection accounts for only a small fraction of the observed North Pacific warming. Local wind stress changes contributed considerably to this warming in the region of the Kuroshio extension. These were not considered in our ocean-only model hindcasts and a coupled ocean-atmosphere model may be required to successfully forecast the positive temperature anomalies that developed in the central North Pacific in the late 1980s. We believe that such a model would have to include also the effect of atmospheric teleconnections from the tropical Pacific which needs to be considered as an additional forcing external to the coupled North Pacific ocean-atmosphere system. The interaction of the extra-tropical and the tropical Pacific climate system on decadal time scales is a major subject of current research (Latif et al. 1997; Gu and Philander 1997; Schneider et al. 1999a, b) and still needs to be further investigated.

Acknowledgements We would like to thank E. Maier-Reimer for his help with the ocean model and K. Rodgers for valuable discussions. This work was sponsored by the EU through the PROVOST and SINTEX projects and by the German government through the project "Klimavariabilität und Signalanalyse".

\section{References}

Anderson DLT, Gill AE (1975) Spin-up of a stratified ocean, with application to upwelling. Deep Sea Res 22: 583-596

Bjerknes J (1964) Atlantic air-sea interaction. Adv Geophys 10: $1-82$

Cane MA, Sarachik ES (1981) The response of a linear baroclinic equatorial ocean to periodic forcing J Mar Res 39: 651-693

da Silva AM, Young CC, Levitus S (1994) Atlas of surface marine data. Available from NODC, NOAA/NESDIS E/OC21, Washington, D.C. 20335, USA 1

Deser C, Alexander MA, Timlin MS (1996) Upper ocean thermal variation in the North Pacific during 1970-1991. J Clim 9: $1840-1855$

Deser C, Alexander MA, Timlin MS (1999) Evidence for a winddriven intensification of the Kuroshio Extension from the 1970s to the 1980s. J Clim 12: 1698-1706

Frey H, Latif M, Stockdale T (1997) The coupled GCM ECHO-2. Part I: the tropical Pacific. Mon Weather Rev 125: 703-720

Gill AE (1982) Atmosphere-ocean dynamics. Academic Press 30: pp 507

Graham NE (1994) Decadal-scale climate variability in the tropical and North Pacific during the 1970s and 1980s: observations and model results. Clim Dyn 10: 135-162

Gu D, Philander SGH (1997) Interdecadal climate fluctuations that depend on exchanges between the tropics and the extra-tropics. Science 275: 805-807

Latif M, Barnett TP (1994) Causes of decadal climate variability over the North Pacific and North America. Science 266: 634-637 
Latif M, Barnett TP (1996) Decadal climate variability over the North Pacific and North America - dynamics and predictability. J Clim 9: 2407-2423

Latif M, Stockdale T, Wolff J, Burgers G, Maier-Reimer E, Junge M, Arpe K, Bengtsson L (1994) Climatology and variability in the ECHO coupled GCM. Tellus 46A: 351-366

Latif M, Kleemann R, Eckert C (1997) Greenhouse warming, decadal variability or El Niño? An attempt to understand the anomalous 1990s. J Clim 10: 2221-2239

Levitus S (1982) Climatological atlas of the worlds ocean. NOAA, Prof Pap 13, US Government Printing Office, Washington D.C., $173 \mathrm{pp}, 17$ microfiche

Miller AJ, Cayan DR, Barnett TP, Graham NE, Oberhuber JM (1994) Interdecadal variability of the Pacific Ocean: model response to observed heat flux and wind stress anomalies. Clim Dyn 9: 287-302

Miller AJ, Cayan DR, White WB (1998) A westward-intensified decadal change in the North Pacific thermocline and gyre-scale circulation. J Clim 12: 3112-3127

Münnich M, Latif M, Venzke S, Maier-Reimer E (1998) Decadal oscillations in a simple coupled model. J Clim 12: 3309-3319

Namias J (1959) Recent seasonal interactions between the North Pacific waters and the overlying atmospheric circulation. J Geophys Res 64: 631-646

Namias J (1969) Seasonal interactions between the North Pacific and the atmosphere during the 1960s. Mon Weather Rev 97: 173-192

Neelin JD, Latif M, Jin FF (1994) Dynamics of coupled oceanatmosphere model: the tropical problem. Annu Rev Fluid Mech 26: $617-659$

Nitta T, Yamada S (1989) Recent warming of tropical sea surface temperature and its relationship to northern hemisphere circulation. J Meteorol Soc Jpn 67: 375-383

Parker DE, Folland CK, Bevan A, Ward MN, Jackson M, Maskell F (1995) Marine surface data for analysis of climate fluctuations on interannual to century time scales. In: Martinson et al. (eds) Natural climate variability on decadal to century time scales. National Academy Press, pp 241-250

Paulson CA, Simpson JJ (1977) Irradiance measurements in the upper ocean. J Phys Oceanogr 7: 952-956
Peng S, Robinson WA, Hoerling MP (1997) The modeled atmospheric response to midlatitude SST anomalies and its dependence on the background circulation states. J Clim 10: 971-987

Roeckner E, Arpe K, Bengtsson L, Dümenil L, Kirk E, Lunkeit F, Ponater M, Rockel B, Sausen R, Schubert S, Windelband M (1992) Simulation of the present day climate with the ECHAM model: impact of model physics and resolution. Report 93, Available from MPI für Meteorologie, Bundesstr. 55, 20146 Hamburg, Germany

Schneider N, Barnett TP, Latif M, Stockdale T (1997) Warm pool physics in a coupled GCM. J Clim 9: 219-239

Schneider N, Venzke S, Miller AJ, Pierce D, Barnett TP, Latif M, Deser C, Alexander MA (1999a) Coupling of mid-latitude and tropical Pacific via the oceanic thermocline. Geophys Res Lett 26: $1329-1332$

Schneider N, Miller AJ, Alexander MA, Deser C (1999b) Subduction of decadal North Pacific temperature anomalies: observations and dynamics. J Phys Oceanogr (in press)

Suarez MJ, Schopf PS (1988) A delayed action oscillator for ENSO. J Atmos Sci 45: 3283-3287

Tourre YM, Kushnir Y, White WB (1999) Evolution of interdecadal variability in SLP, SST and upper ocean temperatures over the Pacific ocean. J Phys Oceanogr 29: 1528-1541

Trenberth KE, Hurrel JW (1994) Decadal atmosphere-ocean variations in the Pacific. Clim Dyn 9: 303-319

Venzke S, Allen MR, Sutton RT, Rowell DP (1999) The atmospheric response over the North Atlantic to decadal changes in sea surface temperature. J Clim 12: 2562-2584

Wolff JO, Maier-Reimer E, Legutke S (1997) HOPE, The Hamburg Ocean Primitive Equation Model. Technical Report available from DKRZ, Bundesstr.55, 20146 Hamburg, Germany

Xu W, Barnett TP, Latif M (1998) Decadal variability in the North Pacific as simulated by a hybrid coupled model. J Clim 11: 297311

Zhang RH, Levitus S (1997) Structure and cycle of decadal variability of upper ocean temperature in the North Pacific. J Clim 10: $710-727$ 